\title{
At the helm: resources for physician leaders
}

\section{Lessons Learned: Reflections of Canadian Physician Leaders \\ Chris Carruthers, editor \\ Canadian Medial Association and \\ Canadian Society of Physician Executives; 2009.}

Effective Medical Leadership

Bryce Taylor MD

Rotman/UTPress; 2010.

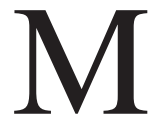
edicine in Canada is enjoying a resurgence of social connectivity and accountability, reconnection to relationships and communities, and integration of evidence and experience. This shift has not come about as a matter of circumstance; rather, generations of skilled and savvy medical leaders have inspired and facilitated change on the individual and the system level. Sir William Osler was and still is right: "The practice of medicine is an art, not a trade; a calling, not a business; a calling in which your heart will be exercised equally with your head."

Lessons Learned: Reflections of Canadian Physician Leaders, a delightful collection of short essays, celebrates the diversity and excellence of physician leadership in this country. Indeed, many of the authors have inspired and challenged generations of medical students and physicians: these are the current day heroes of leadership.

Busy students and physicians will love this book. Each chapter is written in the engaging first person, structured in focused bullet points and short narratives, complemented by photographs and quotes, and packed with practical and courageous advice. Captain Paul Thistle, who shares his experience running a hospital in Zimbabwe where he was responsible for providing care for 250000 people with a budget of $\$ 40000$ amid 1 trillion per cent inflation, captures three key principles of

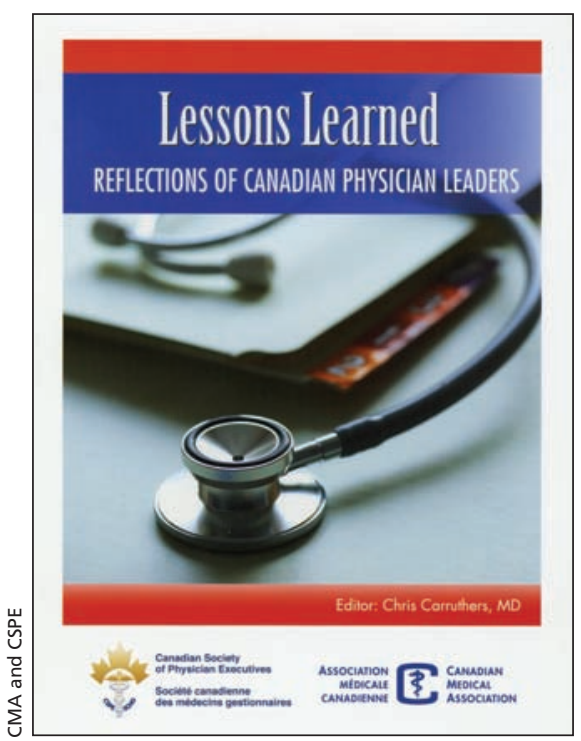

leadership: ability, availability and affability. Astronaut Dave Williams, sharing his blended experience in healing and exploration, reminds us of two powerful constructs: first, that failing to prepare is the same as preparing to fail and, second, it is essential we never lose sight of the privilege of the relationships we have with our patients, particularly in the context of our dayto-day challenges.

Surprisingly, of 19 physician contributors, only 4 are women. Danielle Martin, Major Karen Breeck, Sylvia Creuss and Judith Kazimirski have all made substantial contributions to health care in different ways and share several powerful observations. First, physicians need to take an active and engaged role in leadership in health. Second, physicians benefit from personal and professional support and training for their leadership work. Third, physicians benefit from taking thoughtful risks and challenging the status quo and, fourth, stay tightly connected with other innovative and energetic leaders. Of note, Sylvia Creuss coauthored her contribution with her husband, Dr. Richard Cruess. Their work is touching, poignant, and inspirational as they share their professional success in the context of their commitment and affection for each other and their family.

Three other themes dominate this work.

The first is the power of going back to school. Many of these featured leaders returned to formal training and education to develop skills to complement their medical expertise. Brian Goldman, for example, parlayed a talent in writing with formal training at Ryerson and is now an internationally respected powerhouse of knowledge translation and dissemination in popular media. Another physician, Chris Carruthers coupled his talents in medicine with interests in administration, completed a master's in business administration, and moved on to leave a positive and innovative mark in medical leadership across Canada.

Second, the power of street credibility is strong and important. Repeatedly, leaders emphasize the need to stay connected with patients, patient care and front line health care providers. Dana Hanson, for example, strongly encourages leaders to maintain a clinical practice at all costs.

Finally, a few leaders speak of the importance of personal health and sustainability. Several leaders credit their partners and spouses, family members, friends, and colleagues with their successes. Others speak strongly of the personal costs of leadership and share practical tips on self care and health promotion. Perhaps most powerfully, Hanson shares a story told by another great Canadian leader, Michael Myers, an international expert in physician health and well-being, of a physician patient who seeks professional help because he does not want his tombstone to read "Great Physician, Lousy Father."

Effective Medical Leadership is a 
very different book on Canadian medical leadership. Based on years of surgical leadership, Dr. Bryce Taylor shares personal insights, quotes and evidence to guide the novice leader through the initial rudiments of leadership and management (and beyond). That said, while leadership is a clear theme from time to time, management is the dominant theme of the work.

The diversity of content is impressive: time management, quality and safety, strategic planning, data collection, financial management, ethics, media relations, palliative care, accreditation and aspects of leadership and management. These topics are presented thoroughly, anchored in references and case examples, and are applicable to the context of urban academic hospitals. This diversity, however, comes at the cost of coalescence and flow. The style of the text is better suited to a blog or other real-time digital resource, than a linear text. In addition, some readers may feel isolated from the case examples and general language that does not often reflect gender, generational, or cultural diversity.

Taylor's insights are excellent, although they are largely limited to academically oriented hospital practitioners in surgical specialties. There is little to no

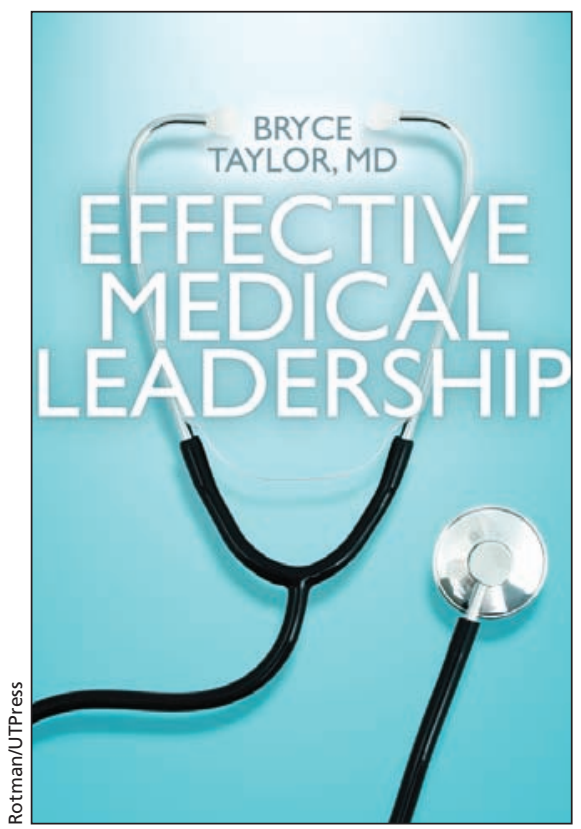

mention of the complexities of mental health care, community practice, or laboratory practice; readers in these specialties will find little familiarity or practical advice here. Indeed, inaccurate use of words like "schizophrenic" pepper the book with an unintended tone of stigma. Finally, topics related to physician resource sustainability are somewhat limited to the disruptive physician or the addicted physician and topics such as resilience, sustainability, and rehabilitation are only briefly mentioned.

With a firm edit, a revised title and a fleshing out of the essential health human resource themes, Effective Medical Leadership would be excellent. As it stands, it seems best suited to mid- to senior-career new leaders in surgical disciplines.

Leadership is a challenge, no doubt, but also an opportunity to make a difference in the lives of our fellow citizens and a difference in how we lead our lives as individuals. Leaders, such as Osler, stand tall in our history as heroes. It is delightful to see our profession acknowledge and celebrate leadership. As with the patients and communities we serve, physicians also require sources of vision, hope, and innovation to sustain their practice and themselves.

\section{Derek Puddester MD}

Director

Faculty Wellness Program

University of Ottawa

Ottawa, Ont.

\section{Reference}

1. Osler W. Aequanimitas: With other addresses to medical students, Nurses, and Pracitioners of Medicine. 2nd ed. Philadelphia (PA): Blakiston's Son; 1920. p. 386.

CMAJ 2011. DOI:10.1503/cmaj.101766 